\title{
Competências em unidades de informação: metodologia para o desenvolvimento de equipes
}

Simone Faury Dib

\author{
Bibliotecária - REDE SIRIUS/UERJ-Especialista \\ em Inteligência Empresarial e Gestão do \\ Conhecimento - CRIE-COPPE/UFRJ
}

Neusa Cardim da Silva

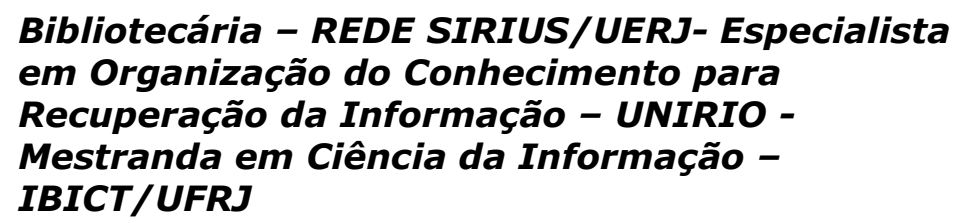

Apresenta a metodologia utilizada para o desenvolvimento de equipes em Unidades de Informação (UIs), elaborada a partir de um trabalho de parceria entre profissionais das área de Biblioteconomia e Psicologia, realizado na Biblioteca de Ciências Sociais C (Direito) da Rede Sirius Rede de Bibliotecas UERJ. A metodologia é fundamentada nos conceitos de employeeship e gestão do conhecimento, e no modelo Pesquisa-Ação. Contempla o desenvolvimento das competências técnicas e das habilidades interpessoais, e sua importância para o trabalho em equipe. Dentre os resultados obtidos a partir da utilização da metodologia, destacam-se melhorias na integração dos membros da equipe e na execução dos processos de trabalho na UI, bem como um maior comprometimento dos profissionais com os objetivos e metas da biblioteca.

Palavras-chave: Cultura organizacional; Desenvolvimento de equipes; Desenvolvimento de competências; Gestão do conhecimento. 


\title{
Competencies in Information Units:methodology for the team's development
}

\begin{abstract}
The paper presents a methodology used for development of teams in Information Units, elaborated from a joint work of librarians and psychologists at the Biblioteca de Ciências Sociais C (Law Course) of Rede Sirius- Rede de Bibliotecas UERJ. This methodology is based on the concepts of employeeship, knowledge management and Action Research model. Its implementation contemplates techniques and interpersonal team abilities. The results were evidenced by team integration and improvement of tasks developed in the Information Units, as well as an involvement of the professionals for accomplishing the proposed goals.
\end{abstract}

Palavras-chave: Organizational culture; Team Development; Development of abilities; Knowledge management.

Recebido em 04.04.2008 Aceito em 24.07.2009

\section{Introdução}

O sucesso de um empreendimento está relacionado a fatores intrínsecos e extrínsecos às organizações. Se, por um lado, é fundamental desenvolver estratégias com foco no cliente, implementar produtos e serviços com valor agregado, buscar constantemente a criatividade e a inovação, por outro, é imprescindível que as organizações monitorem o ambiente em que estão inseridas, para identificar novas demandas, possíveis novos entrantes, a concorrência, entre outros aspectos.

O cenário atual, caracterizado principalmente pela globalização, a competitividade, os avanços tecnológicos e a produção constante de novos conhecimentos, promove impactos, em maior ou menor intensidade, nas estruturas organizacionais (arquitetura organizacional) e nos modelos de gestão. Adaptar-se a esse contexto constitui-se num desafio, considerando-se a diversidade, a transitoriedade e as inovações que the são inerentes.

Assim, procurando se adequar às mudanças e garantir seu crescimento, as organizações se reposicionam estrategicamente e implementam ações que possibilitam o alcance de seus objetivos, investindo em estruturas horizontais em detrimento de estruturas hierárquicas, e adotando modelos de gestão descentralizados que 
privilegiam a delegação de poder, a flexibilidade e o compartilhamento de responsabilidades e de decisões.

No entanto, o aparato tecnológico e as estratégias organizacionais não prescindem dos talentos humanos, pois o indivíduo é o principal detentor das competências intelectuais, técnicas e interpessoais, que se traduzem em um diferencial competitivo e que agrega valor às organizações. Assim, pode-se observar uma valorização do indivíduo e do fazer coletivo, criando-se um espaço de integração e complementaridade o espaço do saber -, que "[...] incita a reinventar o laço social em torno do aprendizado recíproco, da sinergia das competências, da imaginação e da inteligência coletivas" (LÉVY, 2000, p. 26).

Neste sentido, as Unidades de Informação (UIs) vêm realizando ajustes em suas estratégias e implementando ações que valorizem os indivíduos, pois se torna um grande desafio congregar as diferentes contribuições individuais em prol de objetivos comuns, superar barreiras interpessoais e potencializar os canais de comunicação, conferindo valor e sentido ao trabalho realizado, fazendo o todo ser de fato mais do que a soma das diferentes contribuições individuais.

Este artigo apresenta uma metodologia para o desenvolvimento de equipes que atuam em Unidades de Informação (UIs), fundamentada nos conceitos de gestão do conhecimento e employeeship, e no modelo Pesquisa-Ação, visando ao desenvolvimento de competências técnicas e interpessoais, essenciais ao trabalho em equipe.

\section{Desenvolver para crescer: a importância do trabalho em equipe}

$\mathrm{Na}$ atualidade, o trabalho em equipe tornou-se um diferencial competitivo, pois possibilita, através do fazer coletivo, o desenvolvimento de serviços e produtos com valor agregado, na medida em que une pessoas com conhecimentos complementares, tendo metas e objetivos em comum. Trabalhar em equipe favorece, também, o crescimento pessoal de cada indivíduo, uma vez que viabiliza a troca de experiências.

No entanto, para o alcance de resultados positivos não basta apenas reunir as pessoas e formar um grupo, é fundamental que as competências de cada um estejam associadas à responsabilidade e ao comprometimento mútuo com a qualidade dos relacionamentos e dos resultados esperados.

Em nossas interações com as coisas, desenvolvemos competências. Por meio de nossas relações com os signos e com a informação, adquirimos conhecimentos. Em relação com os outros, mediante iniciação e transmissão, fazemos viver o saber. [...] Toda atividade, todo ato de comunicação, toda relação humana implica um aprendizado. Pelas competências e conhecimentos que envolvem, um percurso de vida pode alimentar um circuito de troca, alimentar uma sociabilidade de saber (LÉVY, 2000, p. 27). 
Adotar um programa de desenvolvimento de equipes, que privilegie a aprendizagem e a interação de seus participantes, constitui-se em ação de fundamental importância, não devendo ser entendido como um evento isolado, mas, sim, como um processo contínuo de experimentação e troca.

Para o sucesso do programa e a efetiva integração da equipe, alguns aspectos devem ser considerados, tais como o papel da liderança, a comunicação, a consciência de toda a equipe sobre o seu propósito e suas potencialidades, e o papel profissional de cada um dos seus integrantes.

Uma equipe capacitada, motivada por indivíduos com elevada autoestima, torna-se harmoniosa e comprometida com a missão institucional, num clima de bem-estar geral; o que propicia o desenvolvimento de um ambiente criativo e produtivo.

Assim, como é fundamental que exista sinergia entre as pessoas para que haja cooperação e comprometimento na realização dos objetivos propostos, o conhecimento dos processos operacionais e técnicos deve ser comum a todos, ainda que a atribuição de tarefas seja diferenciada, de acordo com as funções de cada integrante da equipe.

No entanto, não só o treinamento adequado da equipe é garantia de sucesso. É necessário o estímulo ao desenvolvimento do lado emocional dos indivíduos, para que se tornem integrados e garantam a sobrevivência e o crescimento das Unidades de Informação. [...] Os gestores das UI devem perceber que o maior capital de que dispõem é o humano, uma vez que são eles os geradores de recursos. A consciência de que as pessoas são fontes de grandes possibilidades e inesgotáveis soluções e que nenhuma tecnologia poderá substituí-las se constitui em uma efetiva vantagem competitiva (SILVA; DIB, 2002, p.10).

Em equipe, congregar talentos e habilidades complementares em torno de um único objetivo resulta num fazer efetivamente coletivo. A missão, a visão e os objetivos organizacionais devem ser claros e aceitos por todos; os papéis devem ser definidos e as responsabilidades devem ser compartilhadas, propiciando um ambiente equilibrado, tranqüilo e criativo.

\section{Aporte teórico}

A elaboração de uma metodologia que propiciasse a valorização do capital humano por meio do desenvolvimento de suas competências técnicas e habilidades interpessoais, visando à melhoria do processo produtivo e à humanização do trabalho, surgiu a partir de um Programa de Desenvolvimento de Equipes realizado na Biblioteca de Direito da Rede Sirius - Rede de Bibliotecas da Universidade do Estado do Rio de Janeiro (UERJ), idealizado e aplicado por profissionais das áreas de Biblioteconomia e de Psicologia da Universidade. 
Os resultados obtidos com a implementação do programa, evidenciados por um trabalho diferenciado e inovador de valorização e integração de equipes, avalizaram a metodologia utilizada, o que motivou seus mentores a divulgá-la.

Essa metodologia se baseou nos conceitos de employeeship e de gestão do conhecimento, e no modelo de pesquisa-ação, que possuem em comum o foco no indivíduo enquanto agente responsável pelo processo de mudanças.

O employeeship contempla os valores dos indivíduos, na medida em que prioriza a responsabilidade, a lealdade e a iniciativa. Nesse contexto, uma pessoa que se sente responsável pelos resultados da organização demonstra lealdade às outras, contribui para a criação e a manutenção de um espírito de equipe e toma a iniciativa de melhorar e desenvolver continuamente suas atividades, favorecendo a evolução da organização como um todo. Segundo Moller (1996, p. 12), employeeship expressa aquilo "[...] que é preciso para ser um bom funcionário."

Uma organização com employeeship aprende a todo o momento e percebe que investir em seu capital humano, na sua capacitação técnica e no desenvolvimento do seu lado emocional, tornará as pessoas mais flexíveis, responsáveis e com elevada auto-estima, facilitando, principalmente, a implementação de mudanças (SILVA; DIB, 2002, p. 4).

A aplicação desse conceito à UI reafirma a importância da interdisciplinaridade e revela que a sua gestão, quando baseada na valorização daqueles que nela atuam, tem como resultados a integração e a maximização do desempenho da equipe.

A gestão do conhecimento fornece instrumental e metodologias para estimular a inovação e a criatividade, e para identificar e disseminar os diversos saberes que permeiam a organização. Dessa forma, contribui para o desempenho eficaz dos indivíduos e para a geração de novos conhecimentos.

Cabe enfatizar que, para se alcançar a excelência na gestão do conhecimento, devem ser considerados e monitorados os capitais ambiental, estrutural, intelectual e de relacionamento.

O capital ambiental é definido como o conjunto de fatores que descrevem o ambiente onde a organização está inserida. São fatores expressos pelo conjunto das características sócioeconômicas da região (nível de escolaridade, distribuição de renda, taxa de natalidade etc.), pelos aspectos legais, valores éticos e culturais (por exemplo, o empreendedorismo), pelos aspectos governamentais (grau de participação do governo na economia, estabilidade política) e pelos aspectos financeiros, como o nível da taxa de juros e a existência de mecanismos adequados de financiamento à produção.

$[\ldots]$

O capital estrutural pode ser definido como [...] a infraestrutura necessária para fazer a empresa funcionar. Faz parte ainda do capital estrutural a cultura da organização 
$[\ldots]$

O conceito "capital intelectual" refere-se tanto à capacidade, à habilidade e à experiência quanto ao conhecimento formal das pessoas que integram uma organização. O capital intelectual é um ativo intangível que pertence ao próprio indivíduo, mas que pode ser utilizado pela empresa para gerar lucro ou aumentar seu prestígio e reconhecimento social.

[...]

O capital de relacionamento [...] é definido como a rede de relacionamentos de uma organização com clientes, fornecedores e parceiros (CAVALCANTI; GOMES; PEREIRA, 2001, p. 55).

De acordo com Barbalho, o processo de gerir as competências individuais, grupais e organizacionais da equipe constitui-se no cerne da gestão do conhecimento e da otimização dos capitais humano e intelectual. "A base fundamental deixa de ser o desenho dos cargos e passa a ser o conceito dinâmico de habilidades e competências necessárias ao sucesso da organização e dos seus parceiros - clientes, fornecedores, funcionários" (BARBALHO, 2002, p.2).

O modelo de pesquisa-ação é um tipo de pesquisa social, com base empírica, concebido e realizado em estreita associação com a resolução de um problema coletivo. Para tanto, a participação das pessoas nele envolvidas é absolutamente necessária (THIOLLENT, 2003).

O princípio fundamental desse modelo consiste em uma intervenção na organização mediante a efetiva cooperação de seus integrantes para definir o problema e buscar soluções, constituindo-se numa ferramenta para o processo de mudança. Esse modelo tem sido utilizado nas organizações em programas de mudanças planejadas, sendo, ao mesmo tempo, uma abordagem para a solução de problemas (modelo teórico) e um processo de resolução de problemas (conjunto de atividades) (MOSCOVICI, 2003).

Os conceitos de employeeship e de gestão do conhecimento, com ênfase no capital intelectual, nortearam o desenvolvimento teórico desta metodologia, que teve como suporte o modelo de pesquisa-ação, com objetivos de atrair, reter, motivar e desenvolver as competências das pessoas, interpretadas como a reunião dos conhecimentos, habilidades e atitudes, aliados à experiência de cada indivíduo.

\section{Metodologia para o desenvolvimento de competências}

É importante que o gerente da UI assuma o papel de líder no processo de desenvolvimento de competências. Cabe a ele identificar, junto à equipe, o(s) problema(s) existente(s) e propor a implementação de um programa de desenvolvimento de equipes. Ressalta-se que a proposta deve ser aceita por todos os integrantes da equipe para que os resultados sejam positivos. 
Após essa etapa, o gerente deve contatar as instâncias superiores da organização em busca de apoio e parceria, principalmente com o Setor de Recursos Humanos, uma vez que o trabalho a ser desenvolvido é interdisciplinar e envolve um profissional de outra área de atuação, o psicólogo.

\subsection{Etapas da metodologia}

A metodologia compõe-se de cinco etapas: diagnóstico, planejamento, execução, avaliação e acompanhamento.

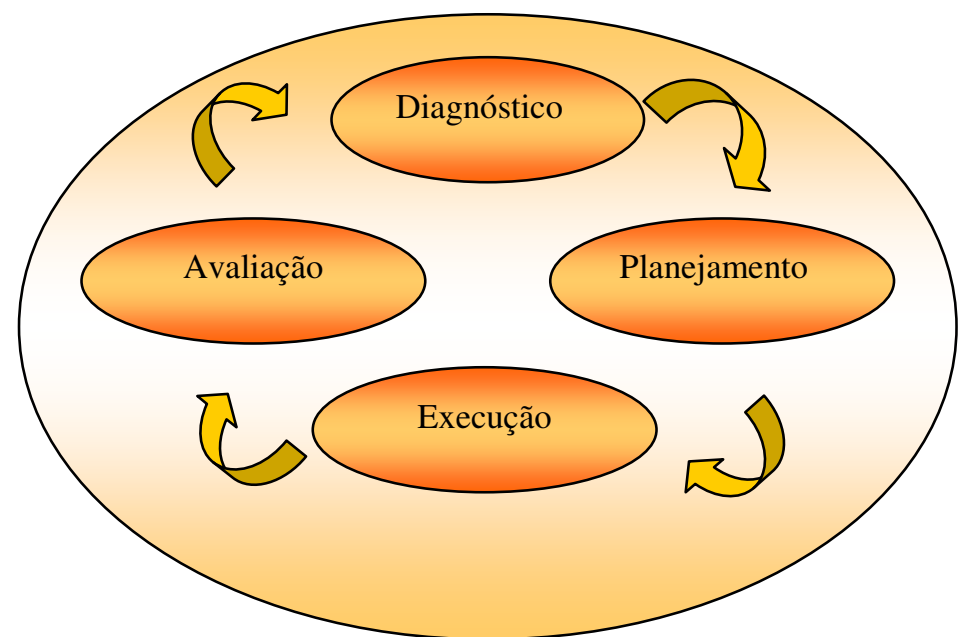

FIGURA 1 - Etapas da metodologia para o desenvolvimento de competências em uma Unidade de Informação

Fonte: Baseado no Ciclo PDCA de DEMING

As etapas do Diagnóstico e do Planejamento poderão ser realizadas pelo gerente da UI e pelo psicólogo ou, ainda, por integrantes da equipe indicados para este fim e pelo psicólogo. As etapas posteriores deverão ser coordenadas por bibliotecário(s) e psicólogo(s) indicados na etapa do Planejamento. É importante enfatizar que toda a equipe, incluindo a gerência, deverá participar das atividades propostas, ratificando a transparência do processo e o comprometimento com o trabalho.

\subsection{Diagnóstico}

O objetivo do diagnóstico é realizar um "retrato da equipe", mapeando suas reais necessidades. Fundamenta-se na análise da situação, na dinâmica e no ambiente da equipe, considerando ainda aspectos externos que possam promover impactos sobre ela.

A etapa do diagnóstico é de suma importância, na medida em que irá nortear todo o trabalho posterior, além de favorecer o envolvimento e o compromisso de todos os integrantes da equipe.

As ações pertinentes a essa etapa são: 
1. Elaborar um instrumento para a coleta de dados, com o objetivo de identificar quais aspectos técnicos e interpessoais deverão ser abordados no programa de treinamento e desenvolvimento de competências;

2. Aplicar o instrumento para a coleta de dados;

3. Consolidar e analisar os dados, elaborando um relatório;

4. Submeter o relatório à equipe para conhecimento;

5. Realizar ajustes no relatório, caso sejam necessários, e submetê-lo novamente à apreciação da equipe.

É importante sublinhar que o diagnóstico será considerado conclusivo se compreender todas as necessidades da equipe e se for por ela validado.

\subsection{Planejamento}

O planejamento deve fundamentar-se no diagnóstico, considerando as informações apresentadas no relatório resultante da coleta de dados, em que foram identificadas as reais necessidades e especificidades da equipe.

Primeiramente, deverá ser elaborado um plano de ações estratégicas que contemple, entre outras informações:

1. Objetivos - gerais e específicos;

2. Metas a serem atingidas em curto, médio e longo prazos;

3. Justificativa e importância;

4. Responsabilidades;

5. Atividades a serem desenvolvidas;

6. Metodologia utilizada;

7. Cronograma das atividades;

8. Local onde serão realizados os trabalhos;

9. Forma de avaliação e de recompensa/reconhecimento;

10.Custo/benefício.

Em seguida, esse documento deverá ser apresentado à equipe, para análise e discussão. Assim, ajustes e reformulações poderão ser realizados, se necessário. Depois de consolidado, o plano de ação deve ser apresentado às instâncias superiores da UI para aprovação.

Nesta etapa, os papéis e responsabilidades de todos os envolvidos devem estar claros, havendo um comprometimento de toda a equipe com o trabalho a ser realizado.

\subsection{Execução}

É o momento de implementar efetivamente o plano de ação elaborado no planejamento.

As ações relacionadas às competências técnicas da equipe devem ser realizadas, prioritariamente, por bibliotecários, uma vez que estes profissionais detêm os conhecimentos técnicos necessários a este fim. A condução das ações voltadas para o desenvolvimento das habilidades 
interpessoais devem ser de responsabilidade do psicólogo, que detém competências inerentes à sua formação. $O(s)$ bibliotecário(s) e o(s) psicólogo(s) indicados deverão sempre implementar ações integradas e atuar de forma conjunta, com imparcialidade, sabendo ouvir e elucidar os problemas apresentados, sem impor suas concepções ${ }^{1}$.

Para o desenvolvimento das competências técnicas da equipe, devem ser realizados encontros previamente agendados, conforme 0 cronograma estabelecido no plano de ação; para que se exponham e se discutam os processos relacionados à UI, definidos na etapa do diagnóstico, utilizando-se como recursos treinamentos específicos e/ou demonstrações práticas de atividades inerentes à rotina da equipe, destacando-se o papel de cada integrante e sua importância para a UI e para a organização como um todo.

Este é um momento único em que várias questões relevantes poderão ser abordadas, tais como:

1. Esclarecimento e explicação das rotinas de trabalho/atividades, mostrando a importância de serem realizadas corretamente para se atingirem os objetivos da UI;

2. Redistribuição das tarefas mediante análise dos próprios integrantes da equipe;

3. Propostas para implementação de novos serviços e produtos, de acordo com o valor percebido pelo cliente;

4. Identificação de problemas no desenvolvimento dos processos e seu realinhamento.

Para o desenvolvimento das habilidades interpessoais, devem ser realizados encontros com temas específicos do relacionamento interpessoal, baseados em uma abordagem vivencial, através de técnicas de dinâmica de grupos, exercícios, jogos, leituras de textos e apresentação de vídeo. Com base na utilização desses recursos, objetivase estimular as pessoas com vistas à reflexão, formação de conceitos e mudanças. É fundamental desenvolver atividades que visem a:

1. Ressaltar a importância da percepção daqueles que estão à nossa volta;

2. Reconhecer e respeitar as diferenças individuais;

3. Mostrar que a união da equipe pode tornar mais fácil a resolução dos problemas;

4. Ressaltar a importância da comunicação;

5. Reconhecer as qualidades que existem em cada pessoa;

6. Destacar que cada um possui uma habilidade específica;

7. Identificar o grau de conhecimento interpessoal da equipe;

8. Avaliar a percepção do grupo em relação ao seu desempenho e envolvimento com as atividades realizadas na UI.

Ao longo dessa etapa, considerando-se os dois níveis de atuação (técnica e interpessoal), não se deve prescindir da elaboração periódica de relatórios; que fornecerão feedback sobre o trabalho desenvolvido,

\footnotetext{
${ }^{1}$ THIOLLENT, Michel. Metodologia da pesquisa-ação. São Paulo: Cortez, 2003.
} 
auxiliando na avaliação do programa de treinamento junto à equipe da UI e, ao mesmo tempo, possibilitarão a realização de ajustes no plano de ação para realinhamento das diretrizes estabelecidas no diagnóstico, se necessário.

\subsection{Avaliação}

A avaliação do trabalho possibilita verificar até que ponto os objetivos e as metas estão sendo atingidos, devendo ser entendida como um processo contínuo. Essa etapa fornece subsídios para o acompanhamento de todo o processo de desenvolvimento das competências.

Os objetivos principais da avaliação são:

1. Verificar se o programa de treinamento e desenvolvimento de competências implementado está atingindo os objetivos propostos;

2. Servir como subsídio para aplicação de um plano de recompensa/ reconhecimento.

Tendo em vista o primeiro objetivo, as avaliações devem ser elaboradas considerando-se os pontos fortes e as oportunidades para melhoria em relação à reação dos participantes, ao aprendizado, à aplicabilidade dos ensinamentos e ao resultado do processo, além da percepção desses processos no âmbito gerencial da UI. As avaliações devem ser feitas após cada encontro, e os registros compilados, analisados e apresentados à equipe, ratificando a transparência do processo.

Caso haja a proposta de se aplicar um plano de recompensa e reconhecimento, este deverá estar explicitado no plano de ação. Embora esse procedimento não seja muito usual nas UIs, poderá ser adotado como forma de motivar a equipe.

\subsection{Acompanhamento}

O acompanhamento é uma etapa que permeia todas as outras, possibilitando a identificação dos gaps em qualquer momento da implementação da metodologia; o que favorece o estabelecimento de ações corretivas que irão assegurar o andamento das atividades, de acordo com o planejamento, para o alcance dos objetivos. Cabe ressaltar que, em alguns momentos, os resultados do acompanhamento podem demandar a reformulação de estratégias, o que implicará rever e alterar o plano de ação.

\section{Considerações finais}


Equipes de trabalho entrosadas e comprometidas com a missão institucional constituem-se no diferencial que agregará valor a qualquer empreendimento.

No entanto, uma equipe precisa de ações que privilegiem o seu desenvolvimento, cujo processo é permeado por elementos-chave, dentre os quais se destacam:

1. A cooperação e a participação de seus integrantes na construção do próprio processo de mudança, implementando ações convergentes com suas especificidades;

2. A compreensão do indivíduo como agente de mudança, considerando-se sua atuação e responsabilidade no processo;

3. A comunicação através de um canal aberto e claro, conferindo transparência e credibilidade, viabilizando, entre outros aspectos, o manejo das resistências, característica inerente ao processo de mudanças.

A metodologia apresentada foi elaborada e aplicada em uma UI, no caso a Biblioteca de Direito da UERJ, em dois momentos. Os resultados positivos demonstraram que a busca do desenvolvimento de equipes em UIs deve ser realizada mediante ações que promovam um espaço de troca, vivência e reflexão, instrumentalizando seus integrantes para a resolução de problemas, bem como para uma adequada percepção e análise das atividades que realizam.

Com isso, o processo de mudança, elemento constante em todas as organizações, pode ser absorvido e traduzido em vantagens para todos, conforme quadro abaixo (QUADRO 1).

QUADRO 1- Atores e vantagens no processo de desenvolvimento de equipes

\begin{tabular}{|c|c|c|}
\hline 1.1.1 & Atores & 1.1.2 Vantagens \\
\hline 1.1 .3 & $\underline{\text { Clientes }}$ & 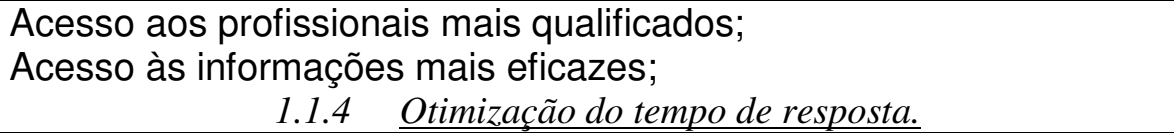 \\
\hline 1.1 .5 & $\begin{array}{l}\frac{\text { Unidade }}{\text { de }} \\
\frac{\text { Informac }}{\underline{\tilde{a} o}}\end{array}$ & $\begin{array}{l}\text { Alinhamento do perfil dos profissionais à missão e objetivos } \\
\text { institucionais; } \\
\text { Acompanhamento do desenvolvimento de seus talentos; } \\
\text { Disponibilidade de produtos e serviços de qualidade que atendam às } \\
\text { necessidades, expectativas e desejos dos clientes. }\end{array}$ \\
\hline 1.1 .6 & Indivíduo & $\begin{array}{l}\text { Gerenciamento de seu desenvolvimento profissional e pessoal; } \\
\text { Aquisição de novos conhecimentos e habilidades e aperfeiçoamento } \\
\text { dos já existentes; } \\
\text { Satisfação pessoal e motivação. }\end{array}$ \\
\hline 1.1 .7 & $\begin{array}{l}\frac{\text { Organiza }}{\text { cão, }} \\
\frac{\text { Parceiros }}{\text { Aliados, }} \\
\frac{\text { etc. }}{\text { Pliats }}\end{array}$ & $\begin{array}{l}\text { Resultados positivos para o negócio; } \\
\text { Vantagem competitiva; } \\
\text { Fortalecimento da marca da Organização. }\end{array}$ \\
\hline
\end{tabular}

Fonte: Dados da pesquisa.

A metodologia apresentada busca conferir qualidade ao ambiente de trabalho, facilitando o desenvolvimento de competências profissionais e do 
relacionamento interpessoal para que o sucesso seja coletivo, beneficiando aqueles a quem os serviços e produtos são destinados: os usuários.

\section{Referências}

BARBALHO, C. R. S. Gestão baseada nas competências. In: SEMINARIO NACIONAL DE BIBLIOTECAS UNIVERSITÁRIAS, 12., 2002, Recife. Anais... Recife: UFPE, 2002. 1 CD-ROM.

CAVALCANTI, M.; GOMES, E.; PEREIRA, A. Gestão de empresas na sociedade do conhecimento: um roteiro para a ação. 6. ed. Rio de Janeiro: Campus, 2001.

FONSECA, D. Gestão por competências. Rio de Janeiro, 2002. 13 f. Apostila utilizada no curso de Pós-graduação Lato Sensu em Gestão do Conhecimento e Inteligência Empresarial, oferecido pelo CRIE COPPE/UFRJ.

LÉVY, P. A inteligência coletiva: por uma antropologia do ciberespaço. São Paulo: Loyola, 2000.

MOLLER, C. Employeeship: como maximizar o desempenho pessoal e organizacional. São Paulo: Pioneira, 1996.

MOSCOVICI, F. Desenvolvimento interpessoal: treinamento em grupo. Rio de Janeiro: José Olympio, 2003.

SILVA, N. C.; DIB, S. F. Desenvolvendo talentos: a experiência da Biblioteca de Direito da UERJ. In: CONGRESSO BRASILEIRO DE BIBLIOTECONOMIA E DOCUMENTAÇÃO, 20., 2002, Fortaleza. Anais...Fortaleza: UFC, 2002. 1 CD-ROM.

THIOLLENT, M. Metodologia da pesquisa-ação. São Paulo: Cortez, 2003.

\section{Bibliografia}

BARBALHO, C. R. S.; BERAQUET, V. S. M. Planejamento estratégico para unidades de informação. São Paulo: Polis - Associação Paulista de Bibliotecários, 1995.

BELLUZO, R. C. B. Da capacitação de recursos humanos à gestão da qualidade em bibliotecas universitárias: paradigma teórico-prático para ambiente de serviço de referência e informação. São Paulo, 1995. Tese (Doutorado em Ciências da Comunicação) - Escola de Comunicação e Artes, Universidade de São Paulo, 1995.

CIANCONI, R. Gestão da informação na sociedade do conhecimento. Brasília, DF: SENAI/DN, 1999. (Série SENAI Formação de Formadores).

Gestão do conhecimento: visão de indivíduos e organizações no Brasil. 2003. Tese (Doutorado em Ciência da Informação) - Escola de Comunicação, Universidade Federal do Rio de Janeiro, Rio de Janeiro, 2003. 
DIB, S. F.; SILVA, N. C. Unidade de Negócio em Informação (UNInf): o futuro das bibliotecas universitárias na sociedade do conhecimento. Perspect. Ciênc. Inf., Belo Horizonte, v. 11, n. 1, p. 20-31, jan./abr. 2006. KATZENBACH, J. R. Equipes de alta performance: conceitos, princípios e técnicas para potencializar o desempenho das equipes. Rio de Janeiro: Campus, 2001.

. A força e o poder das equipes. São Paulo: Makron. 1994.

MACIEL, A. C.; MENDONÇA, M. A. R. Bibliotecas como organizações. Rio de Janeiro: Interciência; Niterói: Intertexto, 2000.

MOSCOVICI, F. Equipes dão certo: a multiplicação do talento humano. Rio de Janeiro: José Olympio, 1994.

NONAKA, I.; TAKEUCHI, H. Criação de conhecimento na empresa: como as empresas japonesas geram a dinâmica da inovação. 11. ed. Rio de Janeiro: Ed. Campus, c1997.

SPECTOR, P. E. Psicologia das organizações. São Paulo: Saraiva, 2003. 